\title{
The Impact of Cloud Based Information Systems on Organization's Performance
}

\author{
Dr. Ahmed Yass Algrari \\ Cihan University /sulymainya /Kurdistan region/Iraq
}

\begin{abstract}
Cloud computing and mobile applications today are still buzzwords, and important resources in the business strategies of companies. More and more organizations have adopted and currently are using cloud computing and mobile technologies. Big companies developed their own big data centers, private cloud or hybrid cloud as a support for their processes within the shared services architecture. Since Information Systems (IS) process and store a series of sensitive and confidential data. Technological evolution becomes more and more a daily reality for organizations and individuals who use information systems, for supporting their operational activities. This paper focuses the cloud based information systems and discus the impact of these information systems on organization's performance. Organizational productivity is one of the most widely used accounting performance indicator of evaluation of the information systems value, Among the financial marketbased measures, adopters of the performance-based approach towards determining IS value often utilize return on assets, performance measures have proven to be useful in identification of the business value of the information technology and information systems used in the organizations as they provide simple quantifiable indicators.
\end{abstract}

Keywords: Cloud computing, information systems, Information systems value, organization performance

\section{Introduction}

Nowadays, organizations continue to grow larger and larger, not only in the number of employees, but in the number of departments and type of employees. In cases such as these, cloud computing is a resource that is readily available to help organizations meet their needs and accomplish their goals. Especially in small businesses, cloud computing is an excellent technological tool that can benefit the business. All businesses need to respond to competition by making better use of Internet services and offering more incentives than their competitors. Cloud computing can help business shift their focus to developing good business applications that will bring true business value. It can serve as a vital improvement to the business by acting as a potential disruptive innovation for its employees. However, these businesses should be mindful of the uses of cloud computing, as well as which services provide suitable public or private clouds [1]. cloud computing is an innovative way to increase business value and productivity in the workplace, the use of this technology should be only for the people or workers who have access to the Internet right away. In some case, offline workers cannot use this technology because it is solely offered online [2]. Therefore, cloud computing, in order for it to be used successfully, must only be used by companies that meet specific criteria with specific needs and resources.

This paper will discuss the use of cloud computing and how cloud computing technology focuses on the impact of cloud based IS on performance of organization. We will provide a definition of cloud computing and how it is currently being used. Then we focus on business value of information system . ultimately we will focus on the impact of cloud technology on business development Furthermore, we will explore which type of businesses benefit most from cloud computing effect on organization' performance.

\section{Cloud Computing}

Cloud computing is an emerging field that is expected to change the entire information technology processes and IT market in future. It is changing how we develop, deploy, use the information technology and the infrastructure that it runs on. The cloud is typically built in a multilayered manner. Cloud is comprised of the infrastructures, which are used only on demand and these infrastructures are released after the completion of the task. Clouds can be classified in various types [3]: Public, Private, Hybrid and Virtual Private. The types of cloud are described in brief as follows:

\subsection{Cloud Deployment Model}

Public Cloud - All the services and infrastructure are accessed through Internet and the vendor's premises host the cloud infrastructure. The hardware and software services are supplied as services upon demand. The cost is distributed across the businesses and hence reduces the capital cost. 
Private Cloud - The infrastructure of the cloud model is implemented at the organizations data center and is dedicated to that particular organization, thereby suffering no bandwidth restriction or exposure to outside public. The service can be hosted by the organization or externally hosted, which is cheaper. External hosting can keep the product or service under strict control.

Virtual Private Cloud - It exists within a shared or public cloud.

Hybrid Cloud - It's the mixture of private clouds, for the secured application data and the public cloud for the less concerned application data that saves cost. It is the concept of abstraction of the interaction between the software (operating system) and hardware (servers). This improves speed, makes the system more flexible, reduces implementation costs, etc.[3]

\subsection{Characteristics of Cloud Technology}

The characteristics of cloud technology are as follows [4]:

2.2.1. On-Demand Self Service: A customer can avail any contracted computing resource such as processing power, storage space, or application programs from a service provider without human interaction.

2.2.2. Broad Network Access: The computing resources can be accessed anywhere, anytime with any standard device which can access the web.

2.2.3. Resource Pooling: The computing resources of a provider are assembled to provide the confined service. The pooled resources may be geographically spread across multiple data centers. The computing resources of a provider are shared by several customers. The resources are dynamically assigned to customers depending on the demand.

2.2.4. Rapid Elasticity: Computing resources may be availed elastically by customers. A customer may request more resources when needed and release them when not required. From a customer's point of view the resources are unlimited. The customer pays only for the total resources used.

2.2.5. Measured Service: Cloud computing systems are adaptive systems. They automatically balance loads and optimize the use of resources. A user is permitted to monitor and control resource usage, thereby providing transparency in bills.

\subsection{Cloud Technology Service Models}

There are three basic categories of cloud service models are used. They are as follows [4].

2.3.1. Software-as-a-Service (SaaS): Instead of installing software on the client's machine and updating it with regular patches, frequent version upgrades etc., applications like Word processing, CRM (Customer Relationship Management), ERP (Enterprise Resource Planning) are made available (hosted) over the internet for the consumption of the end-user.

2.3.2. Platform-as-a-Service (PaaS): Instead of buying the software licenses for platforms like operating systems, databases and middleware, these platforms and the software development kits (SDKs) and tools (like Java, .NET, Python, Ruby on Rails) are made available over the Internet.

2.3.3. Infrastructure-as-a-Service (IaaS): This refers to the tangible physical devices (raw computing) like virtual computers, servers, storage devices, network transfer, which are physically located in one central place (data center) but they can be accessed and used over the internet using the login authentication systems and passwords from any dumb terminal or device.

\section{Cloud Based Information Systems}

Computing refers to the information technology service model, where hardware and software services are delivered on-demand to customers across (distributed) IT resources/network in a self-service fashion, independent of the device and location [5]. Resources provided by the cloud can be dynamically adjusted allowing for more optimal resource utilization. Cloud computing emerged as the evolution and technological advancement of the grid and distributed computing, web services, service oriented architecture, utility computing and virtualization [6].

The main value of the cloud computing for businesses derives from offering resources in an economical, scalable and flexible manner, which are affordable and attractive to IT customers and investors [7]. It can be argued that promising business benefits of the cloud resulted in raising high expectations. Gartner Research expects cloud computing to be a $\$ 150$ billion business by 2014 , and according to AMI partners, small and medium businesses are expected to spend over $\$ 100$ billion on cloud computing by 2014 ([7] Despite of the impression that might appear while defining the concept of the cloud, the cloud-based information system does not necessarily have to be implemented and hosted by a third-party. It can be also deployed and supported through organization's internal resources provided that the key principles of the cloud are maintained: resource utilization, virtualized physical resources, architecture abstraction, dynamic scalability of resources, elastic scalability and automated self-provisioning of resources, ubiquity (i.e. device and location independence) and the operational expense model [8]. 


\section{The Importance of Information Systems for organization's performance}

Information systems (IS) value is generally defined as "the impact of investments in particular information systems assets on the multidimensional performance and capabilities of economic entities at various levels, complemented by the ultimate meaning of performance in the economic environment" [9]. The author further clarifies that the gains or losses an organization achieves through implementation of the information systems derives from the way the information system is exploited. Alternatively, IS business value can be defined as "an outcome is the result of introducing a new IT system, a benefit is what is subsequently derived if the new capability is exploited" [10].An example of such outcome of an information system can be that a task performed more quickly and the saved time is used to improve the business processes within an organization.

Form the angle of performance improvements, information technology business value can be characterized as "organizational performance impacts of IT, including productivity enhancement, profit ability improvement, cost reduction, competitive advantage, inventory reduction, measures of performance" [11]. Thus, as can be seen from the abovementioned definitions, the information systems value is often analyzed from the perspective of the positive impact of the information system on the performance of the business processes of the organization. There are several alternative approaches for identification of the IS value, which consider IS value from different angles as well as various organizational levels. Most of the previous studies attempt to identify the IS value through the relationship between IT investment and organizational performance. However, inconsistency of the level of analysis (e.g. country, industry, firm, business unit levels) and differences in utilized metrics (accounting-, performance-, economic-, market-based indicators) lead to contradictory findings regarding the impact of the investment into information technology on organization's productivity. These contradictory findings can range from detecting only insignificant or even negative relationships between IT investment and firm's performance indicators to completely opposite outcomes that indicate considerable investment returns [12]). The inconsistencies in the outcomes of the previously performed studies led to emergence of the concept identified as a "productivity paradox" [13]. "Productivity paradox" raises the issues of discrepancy between organizations' levels of investment into information technology and returns of these investments [12]

There are several major reasons of the negative or non-significant impact of the information technology on the business value that were found in earlier research studies [14]. Among following reasons it is worth to mention measurement problems, lags between IT investments and resulting impacts, redistribution of outputs within the industry and mismanagement [15]. Thus, one of the major downside of the previous research [13] is the focus of the analysis of the information technology impact on the aggregated level that considers the whole organization rather than organization's certain units, departments or separate processes [14].

Such high level of analysis attempts at relating information technology impacts to the overall organization's performance while ignoring the intermediate processes through which IT impacts arise [14]. In order to take into account the intermediary processes, the primary impacts of the information technology should be measured "at a lower operational levels in an enterprise, at or near the site where information technology is implemented" allowing in such a way measurement of the "first-order effects" of information technology implementation [14]. Due to these reasons, process-oriented perspective on the information systems value has become widely adopted by researchers that aimed at demonstrating that the impact of the information systems' investments on organization's performance is intermediated by performance of organization's separate business process [9]. Some of the most widely used approaches for identification of the information systems' value through numerous performance indicators include among others following approaches [9]:

- Performance measures;

- Process-oriented theories;

- Resource-based view;

- Production-oriented model.

Despite of the fact that each of the abovementioned approach considers information systems value from a slightly different angle, the main commonality among them can be described as strong linkage towards quantifying measurement of the information systems value based on certain performance indicators, which can be represented either by financial or operational indicators. Following paragraphs provide description of each group of approaches and consider their advantages as well as drawbacks for identification of the information systems' value.

\section{Organization Performance Measures}

Organization's performance measures have been widely utilized to analyze the IT / ARE business value [9]. Economic measures proved to be most widely used among other performance measures. Such measures include productivity, capacity utilization, product quality, consumer welfare, a set of different profit ratios as well as other market oriented measures [9]. The following represent some of the most widely used performance measures: 


\section{- Accounting performance measures: productivity and capacity utilization.}

Organizational productivity is one of the most widely used accounting performance indicator of evaluation of the information systems value. Despite of the failures of the earlier research in correlating IT investment and increase in firm's productivity, later studies, especially a study made by Brynjolfsson \& Hitt (1996), who analyzed more than 1000 observations, found that computer capital and information systems' labor significantly increase the output of a firm. It was confirmed that computers contribute significantly to the firmlevel output even after the depreciation, possible measurement errors and limitations of the research input data [15]. The main reasons of such positive correlation in the contrast to the earlier research can be referred to three main factors. First of all, the study was conducted a later period of time compared to earlier research (1987-1991), during which computer capital was built-up by the companies more intensively. Secondly, more detailed firm level data was used in the research and finally, usage of the rather large sample of the "Fortune 500 " companies [15].

Other studies also show strong correlation between IT investment and productivity and capacity utilization. Improvements in productivity due to information technology have been detected by applying a production function approach to the analysis of the productivity of IT stock [16] as well as by evaluating intermediate variable such as capacity utilization and inventory turnover, that represent significant variables in determination of return on assets (ROA) [14].

\section{- Financial market-based measures: ROA, market share and other financial indicators.}

Among the financial market-based measures, adopters of the performance-based approach towards determining IS value often utilize ROA, which is calculated as "income from continuing operations before interest expense divided by assets" [17] . Some of the studies that utilized ROA to evaluate IT business value show that companies with IT-enabled strategy and superior IT management skills are more likely to have a sustainable competitive advantage compared to their competitors [17].

Other high level economic performance measures like ROA include, for example, market share, return on sales and value-added as the economic output variables ([14] or Tobin's q indicator. Tobin's q indicator, which is defined as "the capital market value of the firm divided by the replacement value of its assets incorporates a market measure of firm value which is forward-looking, risk-adjusted, and less susceptible to changes in accounting practices". The results of the research show significant positive correlation between IT expenditures and Tobin's q [8].

\section{- Product quality.}

Attempts have been also made to relate IT investment to the improvements in the quality of the organization's products. It is suggested that IT facilitates tracking of the changing customer preferences and adjust better to the changing market environment, develop tailor-made products, utilize data mining tools for identification of the patterns in the data, which as a result leads to the possibility for the companies to create better products for their customers [8]. Other studies also showed the negative correlation between the IT capital, production IT purchases and innovation (e.g. Research and Development (R\&D)) as well as IT purchases and inferior quality [14].

\section{- Consumer welfare}

Analysis of the total benefits of consumers based on the consumer surplus approach, showed that IT investment have a significant positive impact on consumer welfare [16]. Thus, it is believed that IT can improve the reliability of the firm's service, reduce transaction errors, improve performance, develop and manufacture more customized products [8], which, as a result, leads to better customer service and, hence, improves

Thus, performance measures have proven to be useful in identification of the business value of the information technology and information systems used in the organizations as they provide simple quantifiable indicators, the use of which allow creating solid business cases for IT investments. Moreover, a relatively high number of the earlier empirical studies with the use of these indicators are available for information technology and business professionals for reference. Despite of this, one significant disadvantage can be identified for the performance measurement approach. This disadvantage refers to the relatively high levels of the performance indicators (often organizational or, at best, business unit levels), which might provide executives with the full picture of the IT investment's consequences but, at the same time, leave out important details of the concrete benefits information system or IT in general can deliver to specific business processes.

\section{Conclusion}

The cloud based information systems play a big role in organization business value and it's performance. Perceived value was represented by the perceived improvements in information system processes indicated by the organization's performance. The sources of information systems' value, accuracy, usability, 
comparability, relevance and transparency, which were linked to the capabilities of the information systems' adapted from ([18] was represented by the following capabilities: automational, information processing, geographical and tracking capabilities.

\section{References}

[1]. Staten, J. (2008). Is Cloud Computing Ready For The Enterprise? Forrester

[2]. Miller, M. (2008).Cloud Computing: Web-Based Applications That Change the Way You Work and Collaborate Online, Indianapolis: Que Publishing, 2008.

[3]. Buyya, Rajkumar, Chee Shin Yeo, and Srikumar Venugopal. "Market- oriented cloud computing: Vision, hype, and reality for delivering it services as computing utilities." High Performance Computing and Communications, 2008.

[4]. V. Rajaraman, “Cloud Computing," RESONANCE, March 2014, pp. 242-258.

[5]. Marston, S., Li, Z., Bandyopadhyay, S., Zhang, J., \& Ghalsasi, A. (2011). Cloud computing —The business perspective. Decision Support Systems, 51(1), 176-189.doi:10.1016/j.dss.2010.12.006.

[6]. Koehler, P., \& Anandasivam, A. (2010). Cloud Services from a Consumer Perspective. AMCIS 2010. Retrieved from http://citeseerx.ist.psu.edu/viewdoc/download?doi=10.1.1.174.6121\&rep=rep1\&type=p df.

[7]. Motahari-Nezhad, H., Stephenson, B., \& Singhal, S. (2009). Outsourcing Business to Cloud Computing Services: Opportunities and Challenges. LABs of HP. Retrieved from : http://dl.acm.org/citation.cfm?id=2330685.

[8]. Bhardwaj, S., Jain, L., \& Jain, S. (2010). Cloud Computing: A Study of Infrastructure as a Service (IAAS). International Journal of Engineering and Information Technology, 2(1), 60-63. Retrieved from http://ijeit.org/index_files/vol2no1/CLOUD COMPUTING A STUDY OF.pdf.

[9]. Schryen, G. (2012). Revisiting IS business value research: what we already know, what we still need to know, and how we can get there. European Journal of Information Systems,22(2), 139-169.oi:10.1057/ejis.2012.45.

[10]. Alshawi, S., Irani, Z., \& Baldwin, L. (2003). Benchmarking information technology investment and benefits extraction. Benchmarking: An International Journal, 10(4 ) 14-423. doi:10.1108/14635770310485015.

[11]. Melville, N., Kraemer, K., \& Gurbaxani, V. (2004). Review: Information Technology and Organizational Performance: An Integrative Model of IT Business Value. MIS quarterly, 28(2), 283-322..

[12]. Mooney, J. G., Gurbaxani, V., \& Kraemer, K. L. (1996). A process oriented framework for assessing the business value of information technology. ACM SIGMIS Database, 27(2),68-81. doi:10.1145/243350.243363.

[13]. Baily, M. N., \& Gordon, R. J. (1988). The Productivity Slowdown, Measurement Issues, and the Explosion of Computer Power, 1988(2), 347-431.[14] Barua, A., Kriebel, C. H., \& Mukhopadhyay, T. (1995). Information Technologies and Business Value: An Analytic and Empirical Investigation. formation Systems Research, 6(1).

[14]. Brynjolfsson, E., \& Hitt, L. (1996). Paradox Lost? Firm-level Evidence on the Returns to Information Systems Spending. Management Science, 42(4), 541-558.

[15]. Hitt, L. M., \& Brynjolfsson, E. (1996). Productivity, Business Profitability, and Consumer Surplus: Three Different Measures of Information Technology Value. MIS Quarterly,20(2), 121. doi:10.2307/249475.

[16]. Dehning, B., \& Stratopoulos, T. (2002). DuPont analysis of an IT-enabled competitive advantage. International Journal of Accounting Information Systems, 3(3), 165-176.doi:10.1016/S1467- 0895(02)00032-5.

[17]. Davenport, T. H., \& Short, J. E. (1990). The New Industrial Engineering: Information Technology And Business Process Redesign. Sloan Management Review, 31(4). 